\title{
Some Investigations on Effect of Notch on Dynamics Characteristics of Cantilever Beams
}

\author{
S. H. Gawande and R. R. More \\ Department of Mechanical Engineering, M. E. Soicetys College of Engineering, Pune, S. P. Pune University, India.
}

(Received 2 August 2015; accepted 26 August 2016)

Beams are very important as per engineering applications is concern and it undergoes different type of loading. Because of different type of loadings there may be chance of failure of structures due to generation of notch. Therefore notch depth and its location are the main parameters for the vibration analysis of beams. The notch depth and its position may affect the natural frequency. Hence, it is essential to study the effect of notch depth and its position on modal natural frequency of the beam for the good performance and its safety. This paper work focus on the examination of these changes, which are useful for identification of notch place.The material of the beam is seleced as mild steel. In this work the comprehensive analysis of cantilever beam with and without notch has been done using analytical analysis and finite element method (FEM) with the help of ANSYS and experimentally using modern National Instruments (NI) Lab-view technique. An experimental set up was developed in which a cantilever beam was excited by a hammer and the response was obtained using an accelerometer.This method describes the relation between the various dynamics characteristics as modal natural frequency and notch depth, modal natural frequency with notch location. This paper focus on the study of dynamic properties of cantilever beams subjected to free vibration under the influence of notch at different points along the length.

\section{NOMENCLATURE}

$\begin{array}{ll}d & \text { Depth of notch }(\mathrm{mm}) \\ L & \text { Length of the beam } \mathrm{mm} \\ l & \text { Notch location from fixed end }(\mathrm{mm}) \\ l_{c} & \text { Notch location from free end }(\mathrm{mm}) \\ A & \text { Cross-sectional area }\left(\mathrm{mm}^{2}\right) \\ B & \text { Width of the beam }(\mathrm{mm}) \\ H & \text { Height of the beam }(\mathrm{mm}) \\ \rho & \text { Mass density }\left(\mathrm{kg} / \mathrm{mm}^{3}\right) \\ E & \text { Modulus of elasticty }(\mathrm{MPa}) \\ I & \text { Second moment of inertia }\left(\mathrm{mm}^{4}\right) \\ Z & \text { Dimensionless parameter } \\ \mu & \text { Poisson's ratio } \\ K_{J} & \text { Coefficient of torsional spring } \\ \omega_{n} & \text { Natural frequency of free vibration of } \\ & \text { uncraked beam. } \\ \omega_{c} & \text { Natural frequency of free vibration of } \\ & \text { notched beam. } \\ \lambda & \text { Frequency parameter } \\ S & \text { Crack depth ratio }\end{array}$

\section{INTRODUCTION}

The beams are used in many structural and mechanical applications like in steel constructions and machinery industries. It is required that any structure must work properly during its life time; however, because of the damages there may be chance of a breakdown or collapse of the structure. The notch is the crucial part of the damage that is responsible for leading to the break-down of the structure. The notch in the structure is very dangerous due to the static and dynamic loadings. Hence,

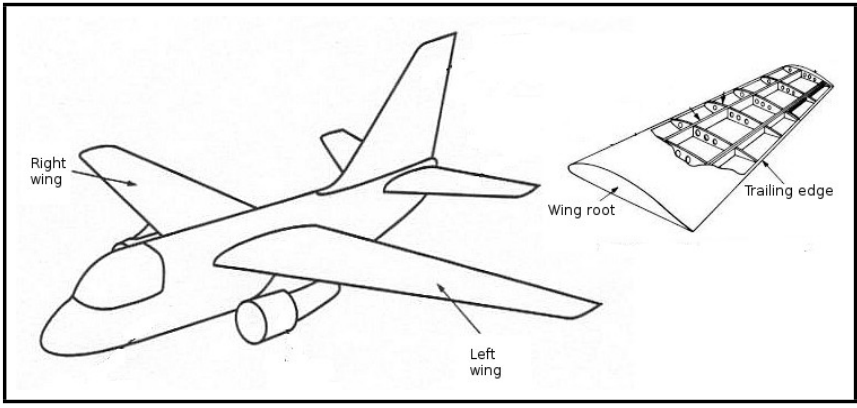

Figure 1. Wings of aeroplane acts as a cantilever.

it is necessary to detect a notch in early stages for the structural health monitoring of the structure. It is very difficult to detect a notch by visual inspection techniques., hence non-destuctive testing such as vibration technique is used for notch detection. If the stucture is defective, there is a change in the stiffness and damping of the structure. A notch on the structure introduces local flexibility, due to this there is change in dynamic properties of the structure. Therefore it is very essential to study the effect of a notch and its position on dynamic properties of the structure like natural frequency, mode shapes, and the amplitude response due to vibration. Cantilever beams are used all around us in many mechanical and structural engineering applications such as: building, bridges, and wings of aeroplane as shown in Fig. 1.

In this paper an effort has been made to study the effect of notch depth and notch position of cantilever beam on modal parameters. In this work, the detailed analysis of a cantilever beam with a notch has been done using analytical analysis, finite element method (FEM) with the help of ANSYS and experimentally using modern National Instruments (NI) Lab- 
view software technique. Extensive research work has been carried out by many researchers on the analysis and effect of crack on different dynamic parameters, but very few worked on the effect of notch on these parameters. Their research has been been reported through recent published journal articles, technical reports, and patents. Loutridisa et al., ${ }^{1}$ developed a new method for notch detection in beams based on instantaneous frequency and empirical mode decomposition. They investigated the dynamic behaviour of a cantilever beam with a breathing notch under harmonic excitation by theoretical and experimental approach. Nahvi and Jabbari ${ }^{2}$ have established an analytical as well as experimental approach for crack detection in cantilever beams by vibration analysis. An experimental setup was designed in which a cracked cantilever beam is excited by a hammer and the response is obtained from an accelerometer attached to the beam. To identify the crack, contours of the normalized frequency in terms of the normalized crack depth and location are plotted. Seyed et al., ${ }^{3}$ proposed a numerical method for open edge-crack detection in an Euler-Bernoulli cantilever beam. Through numerical simulations and experimental tests, they have detected the location and depth of crack. Khadem and Rezaee ${ }^{4}$ established an analytical approach to the crack detection of rectangular plates under uniform external loads by vibration analysis. The flexibility was modeled by the stress-intensity factor and compliance. Owolabi et al., ${ }^{5}$ considered two beams namely cantilever and fixed beam for investigation, after that they initiated crack at seven different location from one end to the other (along the length of the beam), with different range of crack depth ratio. They measured acceleration frequency responses at seven different points on each beam. From the experimental work, they observed that the crack can be detected by analyzing change in natural frequency and amplitudes of frequency response function. Agarwalla et al., ${ }^{6}$ had experimentally analyzed the effect of an open crack on the modal parameters of the cantilever beam subjected to free vibration and compared with result obtained from numerical method. Lee and Chung ${ }^{7}$ has given nondestructive approach for identifying a crack, the location and size of the crack, in a one-dimensional beam-type structure using the natural frequency data. Orhan ${ }^{8}$ had performed an analysis of free and forced vibration cracked beam in order to identify the crack in a cantilever beam. Jassim et al., ${ }^{9}$ performed analytical and experimental investigations to study the effects of a crack on the cantilever steel beam with circular cross section. They determined the extent of the damage magnitude and the location of the cantilever beams. They observed that monitoring the change of the natural frequency is a feasible and viable tool to indicate the damage occurrence and magnitude. Kisa and Gurel ${ }^{10}$ proposed a numerical model that combines the finite element and component mode synthesis methods for the modal analysis of beams with circular cross section and containing multiple non-propagating open cracks. They have given three numerical examples to investigate the effects of location and depth of notchs on the natural frequencies and mode shapes of the beams. Nejad et al., ${ }^{11}$ has given an an- alytical estimation based on the Rayleigh's method, extended for a beam having one or two cracks find natural frequencies and mode shapes in order to overcome weakness of solving eigen value problem. They developed an algebric equation which was solved numerically and then coefficients of trigonometric and hyperbolic terms in mode shapes are found using matrices obtained from compatibility conditions at each point of cracks and boundary conditions. Thalapil and Maiti ${ }^{12}$ developed an analytical method to address both the forward problem of determination of natural frequencies knowing the beam and crack geometry details as well as an inverse problem of detection of crack with the knowledge of changes in the beam natural frequencies. Both long (Euler-Bernoulli) and short (Timoshenko) beams have been examined numerically. Nguyen ${ }^{13}$ has analysed mode shapes of a cracked beam with a rectangular cross section beam using finite element method. He observed that the existence of the crack can be detected based on the mode shapes, when the mode shapes are space curves. Also, when there is a crack, the mode shapes have distortions or sharp changes at the crack position. Thus, the position of the crack can be determined as a position at which the mode shapes exhibit such distortions or sharp changes. Khiem and Toan ${ }^{14}$ have proposed a method for calculating the natural frequencies of a multiple cracked beam and detecting an unknown number of multiple cracks from the measured natural frequencies. Chinchalkar ${ }^{15}$ presented a numerical technique for determining the location of a crack in a slender beam of varying cross-section given the first three natural frequencies of the cracked beam. Jena et al. ${ }^{16}$ has given the fault detection of Multi-cracked slender Euler- Bernoulli beams through the knowledge of changes in the natural frequencies and their measurements. The method is based on the approach of modelling a crack by rotational spring. Barad et al. ${ }^{17}$ has presented detection of the crack presence on the surface of beamtype structural element using natural frequency. Andreausa et al., ${ }^{18}$ developed the characterization of the non-linear response of a cantilever cracked beam to a harmonic loading, adopting a two-dimensional finite element formulation, which was capable of simulating the behaviour of a breathing crack via a frictionless contact model of the interacting surfaces. Saavedra and Cuitino ${ }^{19}$ presented a theoretical and experimental dynamic behaviour of different multi-beams systems containing a transverse notch. Their proposed method is used to evaluate the dynamic analysis response of notched free-free beam and a U-frame when harmonic force is applied. Vigneshwaran and Behera ${ }^{20}$ studied the dynamic characteristics of a beam with multiple breathing notches. They developed a systematic approach which has been adopted to develop theoretical expressions for evaluation of natural frequencies and mode shapes. Saptarshi and Ramanjaneyelu ${ }^{21}$ presented a methodology for detection and quantification of structural damage using modal information obtained from a transfer matrix technique. Dawari and Vesmawala ${ }^{22}$ have detected and located the damage in beam models with different boundary conditions by using modal based damage detection method. Barad et al., ${ }^{23}$ seen 


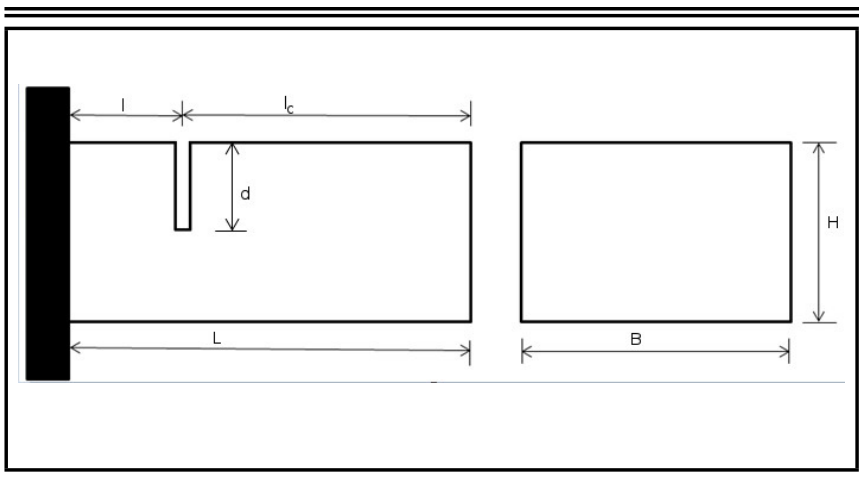

Figure 2. A cantilever beam with notch.

that crack presence by using natural frequency as a parameter. They have studied the effect of crack depth and location on natural frequency. The study of dynamic properties of cantilever beams under the influence of notch at different positions along the length is studied by Gawande and More. ${ }^{24}$

From the literature survey it is observed that comprehensive research work has been carried out by many researchers on the detection, analysis on effect of crack on different dynamic characteristics of structures. But very few worked on effect of notch on these parameters. The objective of this study is to analyse the vibration behaviour of beams subjected to notch by analytical, numerical, and experimental approaches using FEM software ANSYS and NI-LabVIEW system.

\section{ANALYTICAL MODEL FOR CANTILEVER BEAM WITH NOTCH}

In this section analytical model for cantilever beam with notch to determine the three natural frequencies for first three modes i.e. $1^{\text {st }}, 2^{\text {nd }}$, and $3^{\text {rd }}$ is proposed. The cantilever beam of the dimensions $500 \mathrm{~mm} \times 25 \mathrm{~mm} \times 10 \mathrm{~mm}$ is being selected and modelled with notch using wirecut EDM process (depth $2 \mathrm{~mm}, 4 \mathrm{~mm}, 6 \mathrm{~mm}$ ) at two different positions i.e. at $100 \mathrm{~mm}$ and $200 \mathrm{~mm}$ from free end. The proposed analytical model to determine the natural frequencies is the solved by developing code in MATLAB software. These natural frequencies are compared with frequencies obtained by a numerical and experimental approach. Figure 2 shows a cantilever beam with notch. The material for the beam is taken as mild steel having $E=210 \mathrm{Gpa}, A=25 \cdot 10 \mathrm{~mm}^{2}, \rho=7.85 \cdot 10^{-6} \mathrm{~kg} / \mathrm{mm}^{3}$, $\mu=0.32$. In this study, a cantilever beam having a length $L$, height $H$, width $B$ and transverse open edge-notch of depth d is considered as shown in Fig. 2.

A notched cantilever beam is divided in to two parts in order to find out natural frequencies, which are supposed to be joined by a torsional spring as shown in Fig. 3.

Increase in notch depth affects the natural frequency of beam. Stiffness of torsional spring is calculated based on the notch depth and geometry of the beam. The coefficient of the torsional spring is calculated based on $K_{J}$ using following Eq. (1).

$$
K_{J}=\frac{E I}{6\left(1-\mu^{2}\right)} \times \frac{1}{Z}
$$

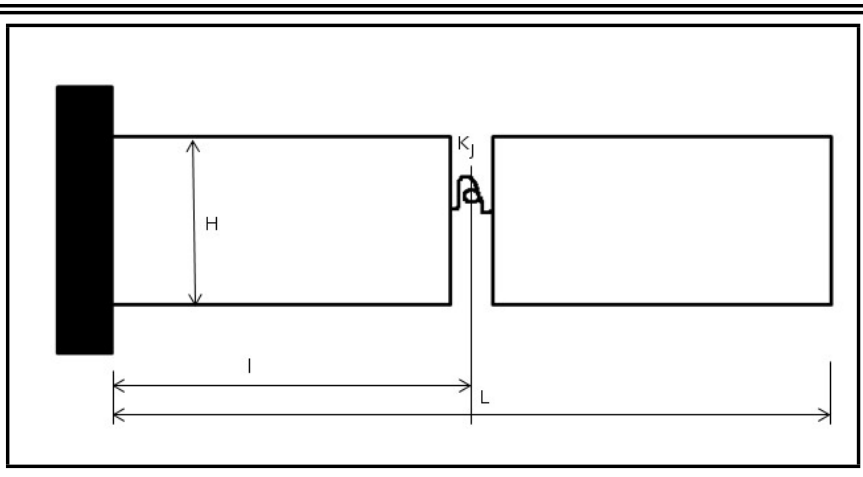

Figure 3. A notched cantilever beam with torsional spring.

where, $E, I$, and $\mu$ are Young modulus, second moment of inertia and Poisson's ratio. The parameter is calculated as follows using Eq. (2):

$$
\begin{aligned}
& Z=1.86 \times S^{2}-3.95 \times S^{3}-16.38 \times S^{4} \\
& -37.23 \times S^{5}+76.81 \times S^{6}-126.9 \times S^{7} \\
& +172 \times S^{8}-143.97 \times S^{9}+66.56 \times S^{10}
\end{aligned}
$$

where $S$ is notch depth ratio i.e. $d / H$.

\subsection{Governing Equation for Cantilever Beam with Notch}

To derive the governing equation, a cantilever beam with torsion spring in case of notch as shown in Fig. 2 is taken to develop mathematical model. The equations describing the cantilever beam is divided into two new function as $Y_{1}(x)$ and $Y_{2}(x)$, which describe the beam equations in the left and right sides of the spring, respectively. The variable $x$ is measured from fixed end of the beam. Notch is assumed to be at $l$ as shown in Fig. 1.

$$
\begin{aligned}
W & =\int_{0}^{l_{c}}\left(\frac{1}{2} \cdot m\left(\frac{\partial y_{1}}{\partial t}\right)^{2}\right) \cdot d x \\
& +\int_{l_{c}}^{L}\left(\frac{1}{2} \cdot m\left(\frac{\partial y_{2}}{\partial t}\right)^{2}\right) \cdot d x \\
X & =\int_{0}^{l_{c}}\left(\frac{1}{2} \cdot E I\left(\frac{\partial y_{1}}{\partial x}\right)^{2}\right) \cdot d x \\
& +\int_{l_{c}}^{L}\left(\frac{1}{2} \cdot E I\left(\frac{\partial y_{2}}{\partial x}\right)^{2}\right) \cdot d x \\
+\frac{1}{2} \cdot K_{J} & \left.\left(\left(\frac{\partial y_{1}}{\partial t}\right)-\left(\frac{\partial y_{1}}{\partial t}\right)\right)^{2}\right|_{x=l_{c}}
\end{aligned}
$$

where $m$ is mass per unit length of the beam.

After derivation of kinematic and potential energy relationships and also using Hamilton equation, the equations of motion is obtained, the equation of motion is obtained as given in Eq. (6).

$$
\delta \int_{t_{1}}^{t_{2}}(W-X) \cdot d t=0 ;
$$




$$
\begin{aligned}
& m\left(\frac{\partial^{2} y_{1}}{\partial t^{2}}\right)+E I\left(\frac{\partial^{2}}{\partial x^{2}}\left(\frac{\partial^{2} y_{1}}{\partial x^{2}}\right)\right)=0 \\
& m\left(\frac{\partial^{2} y_{2}}{\partial t^{2}}\right)+E I\left(\frac{\partial^{2}}{\partial x^{2}}\left(\frac{\partial^{2} y_{2}}{\partial x^{2}}\right)\right)=0
\end{aligned}
$$

by applying the separation of variables $y(x, t)=Y(x) \cdot T(t)$ to Eq. (6), the final equations of transverse vibration are obtained as shown in Eqs. (7) and (8) for the left and right side of notch as follows:

$$
\begin{aligned}
Y_{1}(x)= & B_{1} \cdot \cosh \left(\frac{\lambda x}{L}\right)+B_{2} \cdot \sinh \left(\frac{\lambda x}{L}\right) \\
& +B_{3} \cdot \cos \left(\frac{\lambda x}{L}\right)+B_{4} \cdot \sin \left(\frac{\lambda x}{L}\right) ; \\
Y_{2}(x)= & B_{5} \cdot \cosh \left(\frac{\lambda x}{L}\right)+B_{6} \cdot \sinh \left(\frac{\lambda x}{L}\right) \\
& +B_{7} \cdot \cos \left(\frac{\lambda x}{L}\right)+B_{8} \cdot \sin \left(\frac{\lambda x}{L}\right) ;
\end{aligned}
$$

where $Y_{1}(x)$ and $Y_{2}(x)$ are the equation of the beam for the left and right side of the notch. In these relations, $\lambda$ is defined as follows:

$$
\lambda=\sqrt[4]{\frac{\omega^{2} \rho A L^{4}}{E I}} ;
$$

where, $\omega, \rho, A$, natural frequency, density, and cross-section area of cantilever beam.

For considered cantilever beam, boundary conditions are given as follows;

a. Bending moment and shear force at free end is zero.

b. Slope and displacement at fixed end is zero.

c. Also, displacement, bending moment, shear force at the left- and right-hand side of the notch are equal.

Above conditions are given as per Eqs. (10) and (11).

$$
\begin{gathered}
\left.y_{1}\right|_{x=0}=0 \\
\left.\frac{\partial y_{1}}{\partial x}\right|_{x=0} ; \\
\left.\frac{\partial^{2} y_{2}}{\partial x^{2}}\right|_{x=L}=0 \\
\left.\frac{\partial^{3} y_{2}}{\partial x^{3}}\right|_{x=L}=0 \\
\frac{\partial^{2} y_{1}}{\partial x^{2}}=\left.\frac{\partial^{2} y_{2}}{\partial x^{2}}\right|_{x=l_{c}} ; \\
\frac{\partial^{3} y_{1}}{\partial x^{3}}=\left.\frac{\partial^{3} y_{2}}{\partial x^{3}}\right|_{x=l_{c}} ; \\
\left.\left(\frac{E I}{K_{J}}\left(\frac{\partial^{2} y_{1}}{\partial x^{2}}\right)+\left(\frac{\partial y_{1}}{\partial x}\right)=\left(\frac{\partial y_{2}}{\partial x^{2}}\right)\right)\right|_{x=l_{c}} ;
\end{gathered}
$$

substituting the boundary conditions from Eqs. (10) and (11) into Eqs. (7) and (8), the result can be written in the form Eq. (12) (see on top of the next page), where,
Table 1. Specification of Data acquisition system.

\begin{tabular}{||c|c|c|}
\hline Sr.No. & Parameter & Specification \\
\hline 1 & Brand Make & National Instruments \\
\hline 2 & Number of channels & 4 \\
\hline 3 & Maximum sampling & $51.2 \mathrm{ks} / \mathrm{s}$ per channel \\
\hline 4 & Voltage input & $5 \mathrm{~V}$ \\
\hline 5 & Dynamic range & $102 \mathrm{DB}$ \\
\hline
\end{tabular}

$$
\begin{aligned}
& A_{1}=\cosh \left(\frac{\lambda l_{c}}{L}\right) ; \\
& A_{2}=\sinh \left(\frac{\lambda l_{c}}{L}\right) ; \\
& A_{3}=\cos \left(\frac{\lambda l_{c}}{L}\right) ; \\
& A_{4}=\sin \left(\frac{\lambda l_{c}}{L}\right) ;
\end{aligned}
$$

$$
\begin{gathered}
A_{5}=\cosh (\lambda) ; \\
A_{6}=\cosh (\lambda) ; \\
A_{7}=\cos (\lambda) ; \\
A_{8}=\sin (\lambda) ; \\
K=\frac{K_{J} L}{E I \lambda} .
\end{gathered}
$$

Natural frequency can be obtained by equating the determinant of coefficient of matrix of Eq. (12)to zero. As for nontrival solution determinant must be zero, thus the characteristic equation can be obtained from this determinant by converting sin, sinh, cos, cosh terms into polynomial by using Taylor's series expansion. Thus, from the above polynomial equation's determinant is solved by using MATLAB Software. From the solved determinant characteristic equation be obtained. From this equation natural frequencies of notched cantilever beams are obtained.

\section{EXPERIMENTAL MODEL FOR CANTILEVER BEAM WITH NOTCH}

In order to study the effect of notch on cantilever beam, the required experimental setup as shown in Fig. 4 is developed. It contains instruments like data acquisition hardware (with specifications as shown in Table 1), accelerometer (with specifications as shown in Table 2), impact hammer (with specifications as shown in Table 3), a loaded personal computer [pc] or laptop, test-specimen, power supply for the pc and vibration analyser, and connecting cables for the impact hammer and accelerometer. The experimental analysis is carried out for the cantilever beam to find the natural frequencies of transverse vibration. 


$\left[\begin{array}{cccccccc}1 & 0 & 1 & 0 & 0 & 0 & 0 & 0 \\ 0 & 1 & 0 & 1 & 0 & 0 & 0 & 0 \\ A_{1} & A_{2} & A_{3} & A_{4} & -A_{1} & -A_{2} & -A_{3} & -A_{4} \\ A_{2} & A_{1} & A_{4} & -A_{3} & -A_{2} & -A_{1} & -A_{4} & A_{3} \\ A_{1} & A_{2} & -A_{3} & -A_{4} & -A_{1} & -A_{2} & A_{3} & A_{4} \\ 0 & 0 & 0 & 0 & A_{5} & A_{6} & -A_{7} & -A_{8} \\ 0 & 0 & 0 & 0 & A_{6} & A_{5} & A_{8} & -A_{7} \\ A_{1}+K A_{2} & A_{2}+K A_{1} & -A_{3}+K A_{4} & -A_{4}+K A_{3} & -K A_{2} & -K A_{1} & K A_{4} & -K A_{3}\end{array}\right] \cdot\left[\begin{array}{c}B_{1} \\ B_{2} \\ B_{3} \\ B_{4} \\ B_{5} \\ B_{6} \\ B_{7} \\ B_{8}\end{array}\right]=0$

Table 2. Specification of accelerometer.

\begin{tabular}{||c|c|c||}
\hline Sr.No. & Parameter & Specification \\
\hline 1 & Brand Make & National Instruments \\
\hline 2 & Model no. & PCB $352 \mathrm{C} 33$ \\
\hline 3 & Voltage sensitivity & $100 \mathrm{mv} / \mathrm{g}$ \\
\hline 4 & Frequency range & 0.3 to $12000 \mathrm{~Hz}$ \\
\hline 5 & Electrical connector & $\begin{array}{c}\text { Type/location } 5-44 \\
\text { coaxial/side }\end{array}$ \\
\hline
\end{tabular}

Table 3. Specification of Hammer.

\begin{tabular}{||c|c|c||}
\hline Sr.No. & Parameter & Specification \\
\hline 1 & Brand Make & National Instruments \\
\hline 2 & Model no. & PCB086C03 \\
\hline 3 & Voltage range & 10 DB \\
\hline 4 & Sensitivity element & $\begin{array}{c}\text { Material/type } \\
\text { quartz/Epoxy }\end{array}$ \\
\hline 5 & Electrical connector & $\begin{array}{c}\text { type/location } \\
\text { BNC/Bottom of handle }\end{array}$ \\
\hline
\end{tabular}

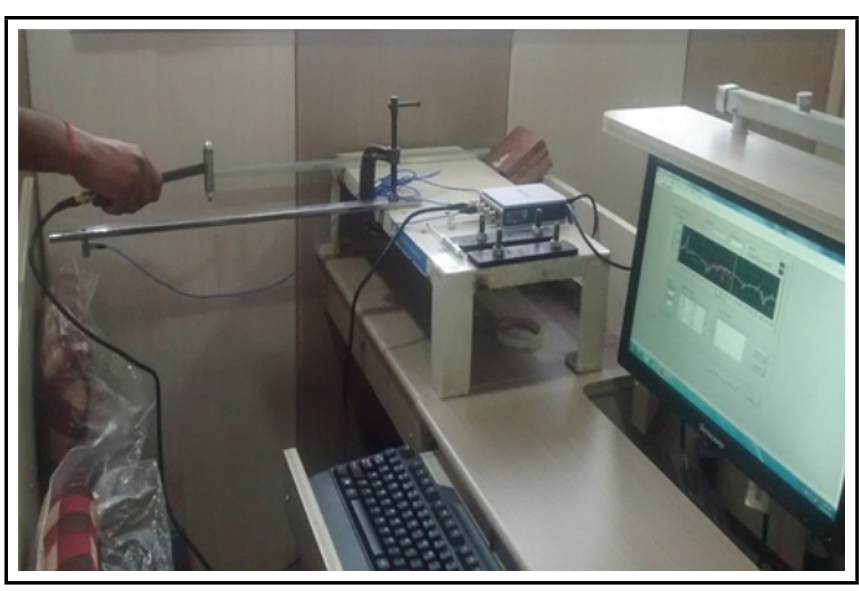

Figure 4. Experimental setup.

\section{NUMERICAL MODEL FOR CANTILEVER BEAM WITH NOTCH}

The numerical analysis is carried out for the cantilever beam to find the natural frequencies of transverse vibration. The cantilever beam made of mild steel $(E=210 \mathrm{Gpa}$, $A=25 \cdot 10 \mathrm{~mm}^{2}, \rho=7.85 \cdot 10^{-6} \mathrm{~kg} / \mathrm{mm}^{3}, \mu=0.32$.) is selected with the dimensions $500 \mathrm{~mm} \times 25 \mathrm{~mm} \times 10 \mathrm{~mm}$ and is being modelled with notch using wirecut EDM process (depth $2 \mathrm{~mm}, 4 \mathrm{~mm}, 6 \mathrm{~mm}$ ) at two different positions i.e. at $100 \mathrm{~mm}$ and $200 \mathrm{~mm}$ from free end. The modal analysis of considered cantilever beam has been done using ANSYS software

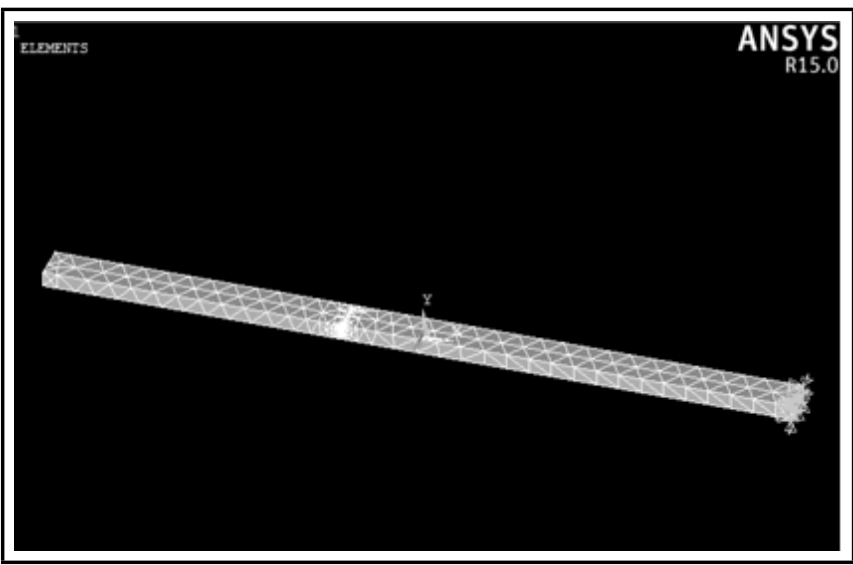

Figure 5. A meshed cantilever beam.

of version 14.5. In order to perform finite element analysis, creation of solid model of cantilever is important. Hence cantilever beam is first modelled in PRO/E WILDFIRE which is excellent CAD software, which makes modelling so easy and user friendly. Then the solid model is transferred in IGES format and exported into the Analysis software ANSYS 14.5. After that the cantilever beam is analysed in three steps. First is pre-processing which involves modelling, geometric clean up, element property definition, and meshing. Next step includes solution of problem, which involves imposing boundary conditions on the model and then solution runs. Figure 5 shows a meshed cantilever beam notch. The next step in sequence is post processing, which involves analysing the natural frequency for different mode of vibration.

\section{RESULTS AND DISCUSSIONS FOR NOTCH}

By using proposed analytical model one can easily find out the natural frequencies for various notch depth and position. Table 4 shows the ratio of natural frequency $\left(\omega_{c} / \omega_{n}\right.$, i.e. ratio of natural frequency of beam with notch to the natural frequency of beam without notch) for various notch depth and locations obtained by using proposed analytical model. The experimental data for cantilever beam is obtained by performing trials using data aquisition system. The frequency response function (FRF) obtained are curve fitted automatically using this software. The experimental data obtained from data aquisition system is plotted in the form of ratio of natural frequency $(\mathrm{c} / \mathrm{n}$, i.e ratio of natural frequency of beam with notch to the natural frequency of beam without notch) for various notch 


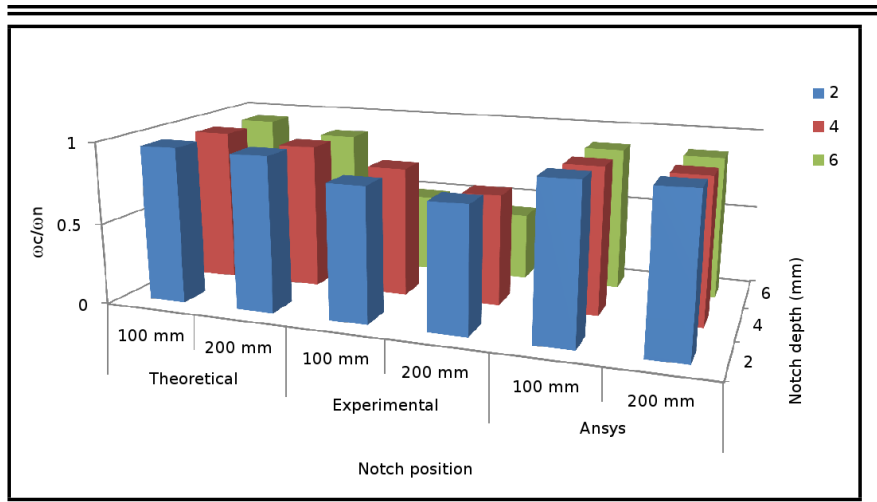

Figure 6. Natural frequency ratio versus notch position versus notch depth for $1^{\text {st }}$ mode.

depth and locations. Table 5 shows the variation of frequency ratio for various notch depth and location obtained experimentally. The effect of various notch depth and position on natural frequency ratio is validated by performing finite element analysis in ANSYS software. Table 6 shows the variation of frequency ratio with repect to various notch depth and location obtained by using ANSYS software. Table 4, Table 5, and Table 6 shows the location of notch from free end (i.e. $100 \mathrm{~mm}$ and $200 \mathrm{~mm}$ ) of cantilever beam.

Figures 6, 7, and 8 are plotted from the Tables 4,5 , and 6 respectively. Figures 6,7 , and 8 shows the graph of natural frequency ratio (i.e. $\omega_{c} / \omega_{n}$ ) versus notch depth and position. Figures 6,7 , and 8 shows the variation of natural frequency ratio for three modes in terms of notch position for various notch depth as $2 \mathrm{~mm}, 4 \mathrm{~mm}$, and $6 \mathrm{~mm}$ for $1^{\text {st }}, 2^{\text {nd }}$, and $3^{\text {rd }}$ mode respectively obtained by analytical, numerical, and experimental approach. From Figs. 6, 7, and 8 it is clear that natural frequency decreases as depth of notch increases. Figures 6, 7, and 8 also shows that there is significant decrease in natural frequency of vibration for notch at position $200 \mathrm{~mm}$ as compared to notch at position $100 \mathrm{~mm}$. Therefore it is seen that natural frequency decreases significantly as position of notch move towards fixed end of cantilever beam. Thus from Figs. 6, 7, and 8 it is observed that behaviour of natural frequency is same for analytical, experimental, and numerical approach. From Table 4, Table 5, Table 6, and Figs. 6, 7, and 8, it is observed that natural frequencies of cantilever beam were greatly affected by notch depth and its position. It is seen that natural frequency of vibration decreases as depth of notch increases. Therefore it seems that decrease in frequency is the function of notch depth. This because of the fact that as notch depth increases implies stiffness of the structure decreases. Thus fundamental frequency decreases as notch depth increases. The frequency was mostly affected by notch when it was located at $200 \mathrm{~mm}$ from free end. Therefore, for cantilever beam it is concluded that natural frequency decreases significantly as notch position moves towards fixed end. From this observation, it is strongly concluded that the frequency decreases greatly at the notch, which ultimately results in maximum bending moment. Therefore, it is concluded that the change in natural frequency is the function of notch position.

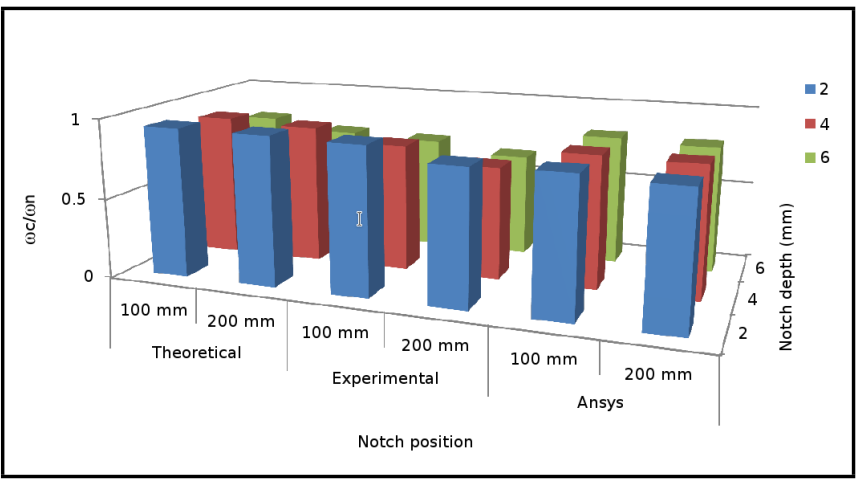

Figure 7. Natural frequency ratio versus notch position versus notch depth for $2^{\text {nd }}$ mode.

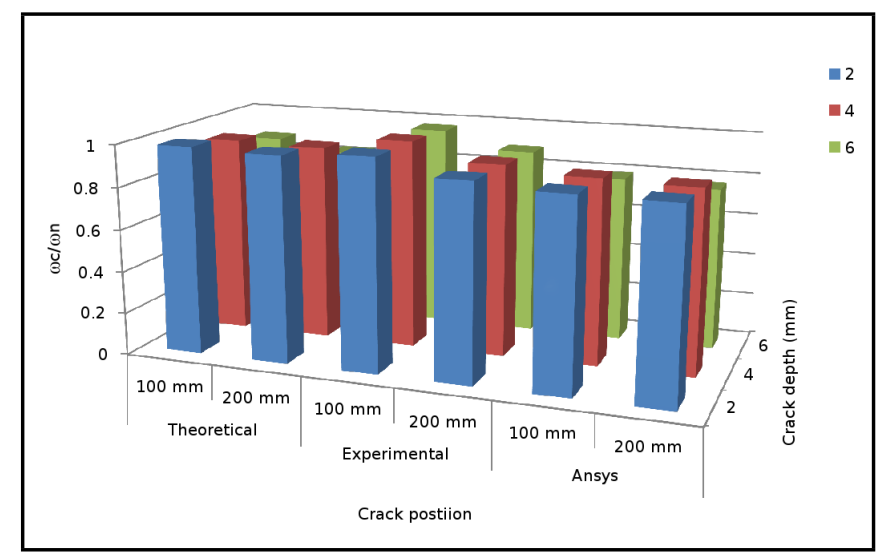

Figure 8. Natural frequency ratio versus notch position versus notch depth for $3^{\text {rd }}$ mode.

\section{CONCLUSIONS}

The primary objective of this paper was to study the effet of notch on natural frequencies in cantilever beam due to variations in depth and position. This objective was achieved with the help of extensive analytical work, computer aided simulation tools and experimental investigations. From the analytical, numerical, and experimental investigations it is seen that natural frequency of vibrating structure is subject to change under the influence of notch, its position, and depth. The natural frequency of the vibrating beam changes significantly in the presence of notch. The frequency was mostly affected by notch when it was located at $200 \mathrm{~mm}$ from the free end. Therefore, for cantilever beam it is concluded that natural frequency decreases significantly as notch position moves towards fixed end. From these observation it is strongly concluded that the frequency decreases greately at the notch which ultimately result in maximum bending moment. Therefore, it is concluded that the change in natural frequency is the function of notch depth and position. So, from analytical, numerical, and experimental results it is observed that by applying the approach proposed in this paper one can easily envion the effect of depth and position of notch on natural frequency.

Conflict of Interests The authors declare that there is no conflict of interests regarding the publication of this paper. 
Table 4. Ratio of $\omega_{c} / \omega_{n}$ from analytical analysis.

\begin{tabular}{||c|c|c|c|c|c|c|}
\hline \multirow{3}{*}{ Mode } & \multicolumn{6}{|c|}{ Ratio of natural frequency $\left(\omega_{c} / \omega_{n}\right)$} \\
\cline { 2 - 7 } & \multicolumn{2}{|c|}{$2 \mathrm{~mm}$} & \multicolumn{2}{c|}{$4 \mathrm{~mm}$} & \multicolumn{2}{c|}{$6 \mathrm{~mm}$} \\
\cline { 2 - 7 } & $(100 \mathrm{~mm})$ & $(200 \mathrm{~mm})$ & $(100 \mathrm{~mm})$ & $(200 \mathrm{~mm})$ & $(100 \mathrm{~mm})$ & $(200 \mathrm{~mm})$ \\
\hline 1 & 0.96 & 0.96 & 0.95 & 0.9 & 0.942 & 0.87 \\
\hline 2 & 0.938 & 0.933 & 0.897 & 0.873 & 0.799 & 0.733 \\
\hline 3 & 0.9858 & 0.975 & 0.94 & 0.931 & 0.877 & 0.828 \\
\hline
\end{tabular}

Table 5. Ratio of $\omega_{c} / \omega_{n}$ from experimental analysis.

\begin{tabular}{|c|c|c|c|c|c|c|}
\hline \multirow{3}{*}{ Mode } & \multicolumn{6}{|c|}{ Ratio of natural frequency $\left(\omega_{c} / \omega_{n}\right)$} \\
\cline { 2 - 7 } & \multicolumn{2}{|c|}{$2 \mathrm{~mm}$} & \multicolumn{2}{c|}{$4 \mathrm{~mm}$} & \multicolumn{2}{c|}{$6 \mathrm{~mm}$} \\
\cline { 2 - 7 } & $(100 \mathrm{~mm})$ & $(200 \mathrm{~mm})$ & $(100 \mathrm{~mm})$ & $(200 \mathrm{~mm})$ & $(100 \mathrm{~mm})$ & $(200 \mathrm{~mm})$ \\
\hline 1 & 0.821 & 0.765 & 0.802 & 0.683 & 0.489 & 0.421 \\
\hline 2 & 0.921 & 0.84 & 0.799 & 0.706 & 0.714 & 0.649 \\
\hline 3 & 0.997 & 0.923 & 0.99 & 0.91 & 0.97 & 0.89 \\
\hline
\end{tabular}

Table 6. Ratio of $\omega_{c} / \omega_{n}$ from finite element analysis in ANSYS.

\begin{tabular}{||c|c|c|c|c|c|c|}
\hline \multirow{3}{*}{ Mode } & \multicolumn{6}{|c|}{ Ratio of natural frequency $\left(\omega_{c} / \omega_{n}\right)$} \\
\cline { 2 - 7 } & \multicolumn{2}{|c|}{$2 \mathrm{~mm}$} & \multicolumn{2}{c|}{$4 \mathrm{~mm}$} & \multicolumn{2}{c|}{$6 \mathrm{~mm}$} \\
\cline { 2 - 7 } & $(100 \mathrm{~mm})$ & $(200 \mathrm{~mm})$ & $(100 \mathrm{~mm})$ & $(200 \mathrm{~mm})$ & $(100 \mathrm{~mm})$ & $(200 \mathrm{~mm})$ \\
\hline 1 & 0.945 & 0.943 & 0.9 & 0.89 & 0.89 & 0.88 \\
\hline 2 & 0.85 & 0.83 & 0.83 & 0.82 & 0.82 & 0.8 \\
\hline 3 & 0.898 & 0.895 & 0.8 & 0.89 & 0.79 & 0.77 \\
\hline
\end{tabular}

\section{REFERENCES}

1 Loutridis, S., Douka, E., and Hadjileontiadisc, L. J. Forced vibration behaviour and crack detection of cracked beams using instantaneous frequency, NDT \& E International, 38 (5), 411-419, (2005). https://dx.doi.org/10.1016/j.ndteint.2004.11.004

2 Nahvi, H. and Jabbari, M. Crack detection in beams using experimental modal data and finite element model, International Journal of Mechanical Sciences, 47 (10), 1477-1497, (2005). https://dx.doi.org/10.1016/j.ijmecsci.2005.06.008

3 Moezi, S. A., Zakeri, E., Zare, A., and Nedaei, M. On the application of modified cuckoo optimization algorithm to the crack detection problem of cantilever Euler-Bernoulli beam, Computers and Structures, 157, 42-50, (2015). https://doi.org/10.1016/j.compstruc.2015.05.008

4 Khadem, S. E. and Rezaee, M. An analytical approach for obtaining the location and depth of an all-over part-through notch on externally in-plane loaded rectangular plate using vibration analysis, Journal of Sound and Vibration, 230 (2), 291-308, (2000). https://dx.doi.org/10.1006/jsvi.1999.2619

5 Owolabi, G. M., Swamidas, A. S. J., and Seshadri, R. Crack detection in beams using changes in frequencies andamplitudes of frequency response functions, Journal of Sound and Vibration, 265 (1), 1-22, (2003). https://dx.doi.org/10.1016/S0022-460X(02)01264-6
6 Agarwalla, D. K. and Parhi, D. R. Effect of crack on modal parameters of a cantilever beam subjected to vibration, Procedia Engineering, 51, 665-669, (2013). https://dx.doi.org/10.1016/j.proeng.2013.01.094

7 Lee, Y. S. and Chung, M. J. A study on crack detection using eigenfrequency test data, Computers and Structures, 38 (3), 327-342, (2000). https://dx.doi.org/10.1016/S00457949(99)00194-7

8 Orhan, S. Analysis of free and forced vibration of cracked cantilever beam, NDT \& E International, 40 (6), 445-450, (2007). https://dx.doi.org/10.1016/j.ndteint.2007.01.010

9 Jassim, Z. A., Ali, N. N., Mustapha, F., and Abdul Jalil, N. A. A review on the vibration analysis for a damage occurrence of a cantilever beam, Journal of Engineering Failure Analysis, 31, 442-461, (2013). https://dx.doi.org/10.1016/j.engfailanal.2013.02.016

10 Kisa, M. and Gurel, M. A. Modal Analysis of multi cracked beams with circular cross-section, Engineering Fracture Mechanics, 73 (8), 963-977, (2006). https://dx.doi.org/10.1016/j.engfracmech.2006.01.002

11 Nejad, F. B., Khorram, A., and Rezaeian, M. Analytical estimation of natural frequencies and mode shapes of a beam having two notchs, International Journal of Mechanical Sciences, 78, 193-202, (2014). https://dx.doi.org/10.1016/j.ijmecsci.2013.10.007

12 Thalapil, J. and Maiti, S. K. Detection of longitudinal cracks in long and short beams using 
changes in natural frequencies, International Journal of Mechanical Sciences, 83, 38-47, (2014). https://dx.doi.org/10.1016/j.ijmecsci.2014.03.022

13 Nguyen, K. V. Mode shapes analysis of a cracked beam and its application for crack detection, Journal of Sound and Vibration, 333 (3), 848-872, (2014). https://dx.doi.org/10.1016/j.jsv.2013.10.006

14 Khiem, N. T. and Toan, L. K. A novel method for crack detection in beam-like structures by measurements of natural frequencies, Journal of Sound and Vibration, 333 (18), 4084-4103, (2014). https://dx.doi.org/10.1016/j.jsv.2014.04.031

15 Chinchalkar. S, Determination of crack location in beams using natural frequencies, Journal of Sound and Vibration, 247 (3), 417-429, (2001). https://dx.doi.org/10.1006/jsvi.2001.3748

16 Jena, P. K., Thatoi, D. N., Nanda, J., and Parhi, D. R. K. Effect of damage parameters on vibration signatures of a cantilever beam, Procedia Engineering, 38, 3318-3330, (2012). https://dx.doi.org/10.1016/j.proeng.2012.06.384

17 Barad, K. H., Sharma. D. S., and Vyas. V., Crack detection in cantilever beam by frequency based method, Procedia Engineering, 51, 770-775, (2013). https://dx.doi.org/10.1016/j.proeng.2013.01.110

18 Andreausa, U., Casinib, P., and Vestronia, F. Nonlinear dynamics of a cracked cantilever beam under harmonic excitation, International Journal of Non-Linear Mechanics, 42 (3), 566-575, (2007). https://dx.doi.org/10.1016/j.ijnonlinmec.2006.08.007

19 Saavedra, P. N. and Cuitino, L. A. Crack detection and vibration behaviour of cracked beam, Computer and Structures, 79 (16), 1451-1459, (2001). https://dx.doi.org/10.1016/S0045-7949(01)00049-9

20 Vigneshwaran, K. and Behera, R. K. Vibration analysis of a simply supported beam with multiple breathing cracks, Procedia Engineering, 86, 835-842, (2014). https://dx.doi.org/10.1016/j.proeng.2014.11.104

21 Sasmal, S. and Ramanjaneyulu, K. Detection and quantification of structural damage of a beam-like structure using natural frequencies, Engineering, 1, 167-176, (2009). https://dx.doi.org/10.4236/eng.2009.13020
22 Dawari, V. B. and Vesmawala, G. R. Structural damage identification using modal curvature differences, IOSR Journal of Mechanical and Civil Engineering, 4, 33-38, (2013).

23 Barad, K. H., Sharma, D. S., and Vyas, V., Crack detection in cantilever beam by frequency based method, Procedia Engineering, 51, 770-775, 2013. https://dx.doi.org/10.1016/j.proeng.2013.01.110

24 Gawande, S. H. and More, R. R. Investigations on effect of notch on performance evaluation of cantilever beams, International Journal of Acoustics and Vibration, 22 (4), 493500, (2017). https://dx.doi.org/10.20855/ijav.2017.22.4495

\section{APPENDIX}

MATLAB code:

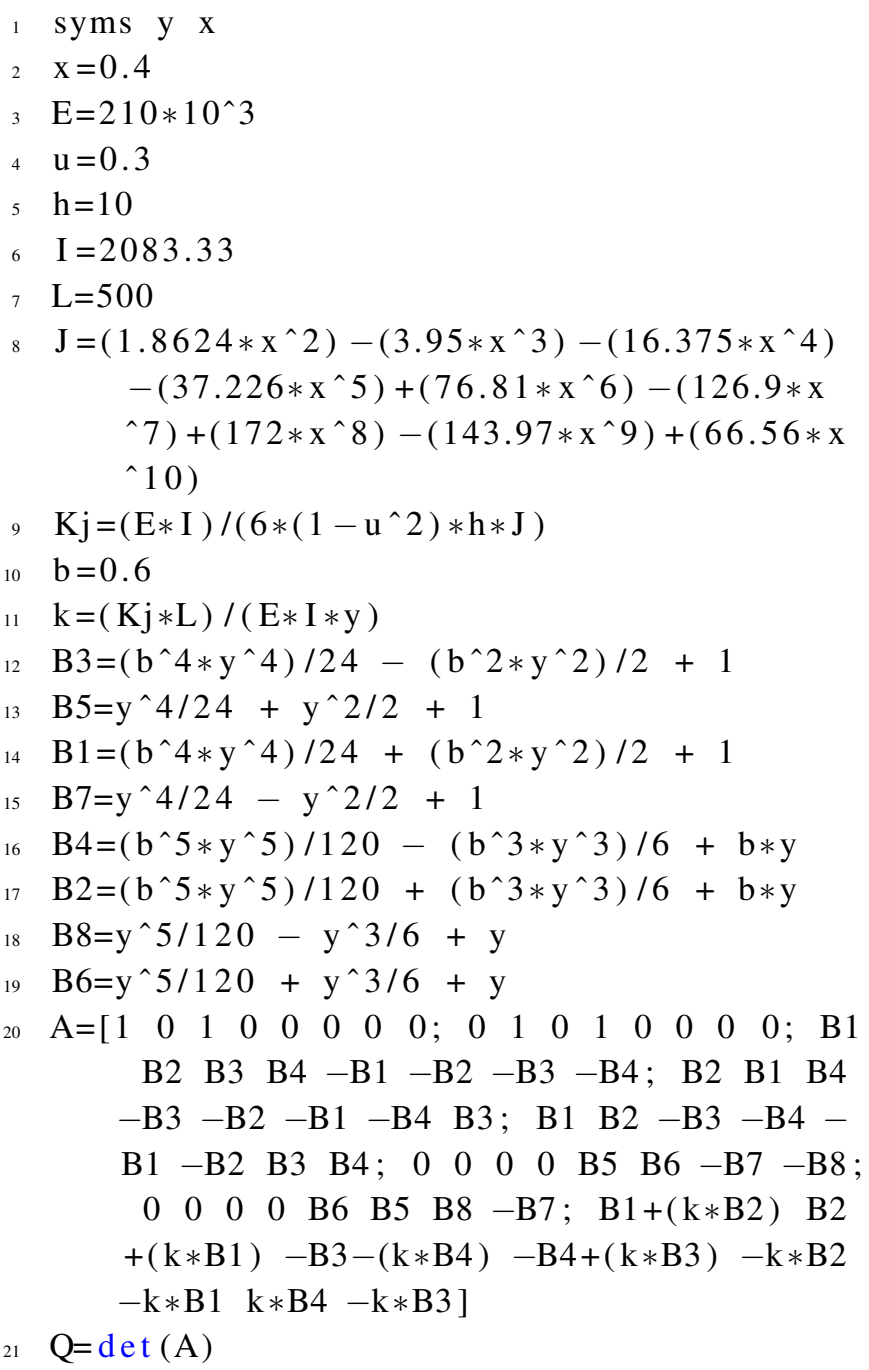

